\title{
Use of cyclic voltammetry to determine the antioxidant capacity of berry fruits: correlation with spectrophotometric
} assays

\author{
M.D. Nikolić ${ }^{1}$, A.N. Pavlović1 ${ }^{1}$ S.S. Mitić ${ }^{1}$, S.B. Tošić1 ${ }^{1}$ M.N. Mitić ${ }^{1}$, B.M. Kaličanin ${ }^{2}$, D.D. Manojlovićn ${ }^{3}$ and \\ D.M. Stankovićt ${ }^{4,5}$ \\ ${ }^{1}$ University of Niš, Faculty of Sciences and Mathematics, Department of Chemistry, Niš, Serbia \\ ${ }^{2}$ University of Niš, Faculty of Medicine, Department of Pharmacy, Niš, Serbia \\ ${ }^{3}$ University of Belgrade, Faculty of Chemistry, Department of Analytical Chemistry, Belgrade, Serbia \\ ${ }^{4}$ University of Belgrade, The "Vinča" Institute of Nuclear Sciences, Belgrade, Serbia \\ ${ }^{5}$ University of Belgrade, Innovation Center of the Faculty of Chemistry, Belgrade, Serbia
}

\section{Summary \\ Background of the study - Among fruits, berry fruits} contain a very large complex of chemical compounds that are responsible for their antioxidant properties. As far as we know there is no data available from cyclic voltammetry studies of berry fruits. Objectives - The first objective of the present work was to investigate the electrochemical properties of antioxidants present in four types of berry fruits: strawberries, blackberries, blueberries and red raspberries. The second objective was to establish the correlation between antioxidant capacities obtained from cyclic voltammograms with those obtained using spectrophotometric techniques. Methods - Evaluation of antioxidant activity of $\mathbf{1 5}$ berry samples (strawberry, blackberry, blueberry and raspberry) has been carried out using cyclic voltammetry (CV). CVs were taken in the potential range between $0 \mathrm{mV}$ and $800 \mathrm{mV}$ with a scan rate of $100 \mathrm{mV} \mathrm{s}^{-1}$. Results - A pronounced anodic current peak observed between $0.524 \mathrm{~V}$ and $0.540 \mathrm{~V}$ in all analyzed berry samples can be ascribed to anthocyanins, which are the major contributors to the antioxidant capacity of investigated berries. Results obtained from CVs were compared with those obtained by using DPPH, ABTS, FRAP and RP assays. ACI parameters were determined for each berry sample by assigning all the assays an equal weight. According to obtained results, the highest ACI had blueberry samples, followed by blackberry, raspberry and strawberry samples. Also, high positive correlations were found between antioxidant capacities deduced from CVs with those obtained using FRAP $\left(R^{2}=0.8630, p=0.0006\right)$, RP $\left(R^{2}=0.7426, p=0.0004\right), \quad D P P H \quad\left(R^{2}=0.7680\right.$, $p=0.0001)$ and ABTS $\left(R^{2}=0.8710, p=0.000002\right)$. In addition, high positive correlations were also found between total phenols, flavonoids, anthocyanins and $C V$ antioxidant capacity $\left(R^{2}=0.8091, p=0.0005\right.$; $\left.R^{2}=0.8341, \quad p=0.0002 ; \quad R^{2}=0.7163, \quad p=0.0007\right)$, respectively. Conclusion - Obtained results showed that the cyclic voltammetry is a suitable method for the determination of the reducing capacity based on the electrochemical properties of compounds under the test.

\section{Significance of this study}

What is already known on this subject?

- Berry fruits are one of the richest sources of polyphenols, but there is no data available from cyclic voltammetry studies of berry fruits.

What are the new findings?

- CV method is suitable for determination of the reducing capacity of polyphenols. The antioxidant power of blueberry is the highest, followed by blackberry, raspberry and strawberry.

What is the expected impact on horticulture?

- The capability of the method to rapidly evaluate the antioxidant activity of berries could be useful for horticulture industry.

Keywords

antioxidant composite index, blackberry, blueberry, raspberry, strawberry, total anthocyanins, total flavonoids, total polyphenols
Abbreviations
CV cyclic voltammetry
ABTS 2,2'-azinobis-3-ethylbenzothiazoline-6-sulfonate
DPPH 2-diphenyl-2-picrylhydrazyl hydrate
FRAP ferric reducing-antioxidant power
RP reduction power Fe(III) to Fe(II)
Trolox 6-hydroxy-2,5,7,8-tetramethylchroman-2- carboxylic acid
TPTZ 2,4,6-tri(2-pyridyl)-S-tirazine
AEAC Ascorbate Equivalent Antioxidant Capacity
TEAC Trolox Equivalent Antioxidant Capacity
ACI Antioxidant Composite Index

\section{Introduction}

Fruits are well-known sources of health-promoting compounds. These compounds include vitamins, minerals and polyphenolic antioxidants. Among fruits, berry fruits are very popular and appreciated because of their beneficial 
health effects. The recommendations based on epidemiological studies are such that berry fruits ensure good protection against the development of diseases caused by oxidative stress, such as cancer, coronary heart disease, diabetes and hypertension (Halvorsen et al., 2002; Seeram, 2008a, b; Szajdek and Borowska, 2008; Paredes-Lópes et al., 2010). The World Health Organization (WHO, 2002) also emphasizes the importance of antioxidant activity of phenolic components, especially from small colorful fruits, for prevention of some diseases. Berry phenolics include flavonoids (anthocyanins, flavonols and flavanols), condensed tannins (proanthocyanidins), hydrolysable tannins (ellagitannins and gallotannins), stilbenoids and phenolic acids (Szajdek and Borowska, 2008; Paredes-Lópes et al., 2010). Because of these natural antioxidants and due to their high concentration and quality diversity, people have a growing interest in the consumption of berries in diet as natural functional food. The total antioxidant activity of berry fruits has been evaluated by various assays and it is given in review works of Giampieri et al. (2012), Rao and Snyder (2010), Lee et al. (2012) and Nile and Park (2014), respectively, and in a study of Tulipani et al. (2008) and Wang and Millner (2009).

However, as far as we know there is no data available from cyclic voltammetry studies of berry fruits. Since the chemical activities of phenolics in terms of their reducing properties as hydrogen or electron-donating agents could predict their potential to act as antioxidants (Yang et al., 2001), studying of electrochemical properties could help to better understand structurally different phenolics. Cyclic voltammetry has numerous advantages over the other mentioned methods; it is simple, rapid and sensitive enough for determination of physiological concentrations of antioxidants.

For that purpose, the first objective of the present work was to investigate the electrochemical properties of antioxidants present in four types of berry fruits: blackberries $(R u-$ bus spp.), blueberries (Vaccinium corymbosum), red raspberries (Rubus idaeus) and strawberries (Fragaria $\times$ ananassa). The second objective was to establish the correlation between antioxidant capacities obtained from cyclic voltammograms with those obtained using spectrophotometric techniques, as well as to establish correlation between the results of antioxidant capacity and total phenol, flavonoid and anthocyanin contents. In addition, the total antioxidant capacities of berry fruits were measured using five in vitro methods: cyclic voltammetry (CV), 1,1-diphenyl-2-picrylhydrazyl free radical (DPPH') scavenging activity, 2,2'-azino-bis(3-ethylbenzothiazoline-6-sulphonic acid) (ABTS) radical cation scavenging activity, ferric reducing-antioxidant power (FRAP) and reduction power (RP) Fe(III) to Fe(II).

\section{Materials and methods}

\section{Chemicals}

Trolox (6-hydroxy-2,5,7,8-tetramethylchroman-2-carboxylic acid) was purchased from Acros Organics (Morris Plains, New Jersey, USA). ABTS (2,2'-azinobis-3-ethylbenzothiazoline-6-sulfonate), DPPH (2-diphenyl-2-picrylhydrazyl hydrate), TPTZ ((2,4,6-tri(2-pyridyl)-S-tirazine), kaempferol, malvidin-3-O-glucoside chloride, coumaric acid, ferrulic acid, caffeic acid, gallic acid, (+)-catechin, rutin and quercetin (HPLC grade), were purchased from Sigma Aldrich (Steinheim, Germany). Cyanidin-3-O-glucoside chloride and quercetin-3-O- $\beta$-glucoside (HPLC grade) were from ChromaDex (Irvine, CA, USA). Folin-Ciocalteu's phenol reagent, potassium peroxodisulfate, ammonium iron(II) sulfate hexahydrate,
iron(III) chloride, potassium hexacyanoferrate(III), sodium hydroxide, sodium acetate, sodium nitrite, sodium carbonate, sodium sulphate, aluminum chloride hexahydrate, sodium dihydrogen phosphate, sodium hydrogen phosphate, ascorbic acid, three chloro acetic acid, hydrochloric acid, acetic acid, and formic acid, were purchased from Merck ${ }^{\circledR}$ (Darmstadt, Germany). Ethanol (96\% by vol.) and methanol (HPLC grade) were from J.T. Baker (Deventer, The Netherlands). Purified water $(18 \mathrm{M} \Omega \mathrm{cm})$, prepared by a MicroMed purification system (TKA Wasseraufbereitungssysteme $\mathrm{GmbH}$, Niederelbert, Germany), was used to prepare all samples and standards.

\section{Samples}

Strawberry fruits of three cultivars (S1-S3), blueberry (Be1-Be3), blackberry (Bc1-Bc5), and raspberry (R1R4) were collected from different commercial plantations in two regions of Serbia. Strawberry samples was selected from Southern Serbia (Leskovac), blueberry samples were originated from Ljig (Western Serbia), blackberry samples were from Valjevo (Western Serbia), whereas the raspberry samples originated from commercial plantations in Ivanjica and Arilje (Western Serbia). Samples were harvested during June-August 2016. The amount of each berry cultivar collected for the analysis was about $500 \mathrm{~g}$.

\section{Preparation of berry fruits}

Ultrasound-assisted extraction has been recently reported as more efficient method for extraction of anthocyanins and flavonols from berry fruits than conventional solvent extraction (Chen et al., 2007; Oancea et al., 2013; Ivanovic et al., 2014). In this work, the ultrasound-assisted extraction with acidified $80 \%$ methanol $(0.01 \%, \mathrm{v} / \mathrm{v} \mathrm{HCl})$ was used to prepare anthocyanin and flavonol-containing extracts from berry samples. Frozen berry fruits were milled in the blender to obtained puree which was subsequently used for extraction. The ultrasonic extractions were performed at room temperature $\left(25^{\circ} \mathrm{C}\right)$ for 15 minutes. Briefly, $2.0000 \mathrm{~g} \pm 0.0001 \mathrm{~g}$ of each berry sample was weighed and the flask with a sample was put into the ultrasonic bath and sonicated for $15 \mathrm{~min}$ at $25^{\circ} \mathrm{C}$. After sonication, the solvent was removed by vacuum evaporation. The extracts were stored in the fridge at $-18^{\circ} \mathrm{C}$ prior to analysis.

\section{Instruments}

An Agilent 8453 UV/Vis spectrophotometer (Agilent Technologies, Santa Clara, California, USA) was used for absorbance measurements and spectra recording, using optical cuvettes of $1 \mathrm{~cm}$ optical path. The $\mathrm{pH}$ measurements were made with Hanna instrument $\mathrm{pH}$-meter (Hanna Instruments, Smithfield, Rhode Island, USA) equipped with glass electrode. Cyclic voltammograms were recorded on a CHI760B instrument (CHInstruments, Austin, Texas, USA). The cell was equipped with GC electrode, an accessory platinum electrode of larger area (Model CHI221, cell top including Pt wire counter electrode) and an $\mathrm{Ag} / \mathrm{AgCl}$ reference electrode (Model CHI111). All measurements were taken at ambient temperature.

\section{Total polyphenolic content (TP)}

Total polyphenols were determined according to the Folin-Ciocalteu procedure (Slinkard and Singleton, 1977; Singleton et al., 1999; Stratil et al., 2006), using gallic acid as standard and expressing the results as gallic acid equivalents (GAE) per gram fresh weight of berry samples (mg GAE $\mathrm{g}^{-1} \mathrm{fw}$ ). All measurements were performed in triplicate. 


\section{Total flavonoid content (TF)}

The total flavonoid content was measured by the aluminum chloride spectrophotometric method described by Zhishen et al. (1999). Catechin was chosen as a standard and the results expressed as gram of catechin equivalents (CE) per gram fresh weight of berry samples ( $\left.\mathrm{mg} \mathrm{CE} \mathrm{g}^{-1} \mathrm{fw}\right)$. The levels of total flavonoid contents in berries were determined in triplicate.

\section{Total anthocyanins (TA)}

The monomeric anthocyanin contents of the acidified methanol extracts were determined using the $\mathrm{pH}$-differential method (Guisti and Wrolstad, 2001). The total anthocyanin content was calculated as micrograms of cyanidin-3-glucoside equivalents $/ 100 \mathrm{~g}$ fresh weight (mg cy-3-glu $100 \mathrm{~g}^{-1} \mathrm{fw}$ ), using an extinction coefficient of $26.900 \mathrm{~L} \mathrm{~mol}^{-1} \mathrm{~cm}^{-1}$ and molecular weight of $449.2 \mathrm{~g} \mathrm{~mol}^{-1}$.

\section{Antioxidative assays}

For DPPH method (Brand-Williams et al., 1995), which is slightly modified, a solution of DPPH $\left(1 \times 10^{-4} \mathrm{~mol} \mathrm{~L}^{-1}\right)$ was prepared in methanol. $5.0 \mathrm{~mL}$ of this solution and $100 \mu \mathrm{L}$ of berry extract were mixed in 10-mL volumetric flask and filled with methanol to the mark. The discoloration of the DPPH radical was measured at $520 \mathrm{~nm}, 30 \mathrm{~min}$ after the reaction started. The Trolox calibration curve was plotted as a function of the decrease in absorbance of DPPH radical scavenging activity. The final results were expressed as millimoles of Trolox equivalents (TE) per gram of fresh weight of berry samples ( $\mathrm{mmol} \mathrm{TE} \mathrm{g}^{-1} \mathrm{fw}$ ).

The ABTS radical scavenging activity was measured using the method of Re et al. (1999) and Arts et al. (2004). $100 \mu \mathrm{L}$ of berry extract was mixed with $3.9 \mathrm{~mL}$ of diluted ABTS radical cation solution. After reaction at room temperature for $6 \mathrm{~min}$, the reduction in absorbance at $734 \mathrm{~nm}$ was measured. The Trolox calibration curve was plotted as a function of the decrease in absorbance of ABTS radical cation scavenging activity. The final results were expressed as millimoles of (TE) per gram of fresh weight of berry samples (mmol TE $\left.\mathrm{g}^{-1} \mathrm{fw}\right)$.

Ferric reducing-antioxidant power (FRAP) assay was performed as previously described by Benzie and Strain (1999). In the FRAP assay, antioxidants in the sample reduce $\mathrm{Fe}^{3+}$-TPTZ complex to the ferrous form at low $\mathrm{pH}(\mathrm{pH}=3.6)$ with an increase in absorbance at $595 \mathrm{~nm}$. FRAP values were expressed as millimoles of $\mathrm{Fe}^{2+}$ equivalents (FE) per gram of fresh weight of berry samples (mmol FE $\mathrm{g}^{-1} \mathrm{fw}$ ).

Reducing power (RP) assay Fe(III) to Fe(II) was determined as described by Oyaizu (1986). Reducing power was expressed in relation to the reducing power of ascorbic acid as a positive control (AEAC, Ascorbate Equivalent Antioxidant Capacity). RP values were expressed as millimoles of ascorbic acid equivalents (AAE) per gram of fresh weight of berry samples (mmol AAE $\mathrm{g}^{-1} \mathrm{fw}$ ).

\section{Electrochemical determination of antioxidant capacity}

Prior to each run, the surface of the glassy carbon electrode was freshly abraded with 1.0, 0.3 and $0.05 \mu \mathrm{m}$ alumina powder, rinsed with redistilled water and degreased in ethanol in ultrasonic bath. Cyclic voltammetric experiments were performed with a solution of standard/extracts mixed with $0.1 \mathrm{~mol} \mathrm{~L}^{-1}$ sodium acetate-acetic buffer ( $\left.\mathrm{pH} 4.5\right)$ at a ratio of $1: 1(\mathrm{v} / \mathrm{v})$ in acidified $80 \%$ methanol. The sodium acetate-acetic buffer also acted as a supporting electrolyte for the CV measurements. The voltammetric experiments were performed at room temperature using an apparatus cell. The scan was taken in the potential range between $0 \mathrm{mV}$ and $800 \mathrm{mV}$ with a scan rate $100 \mathrm{mV} \mathrm{s}^{-1}$ at $2 \mathrm{mV}$ intervals. Cyclic voltammograms were also recorded for Trolox, vitamin E equivalent, in the concentration range $\left(2-80 \mu \mathrm{mol} \mathrm{L}^{-1}\right)$ (Piljac-Zegarac et al., 2010; Veljković et al., 2013). A calibration curve, the area below the major voltammetric anodic peak $\left(Q_{500}\right)$ versus concentration (c) obtained for this standard, was used to calculate TEAC (Trolox Equivalent Antioxidant Capacity) of studied berries.

\section{Antioxidant composite index}

Antioxidant potency composite index was calculated for each sample as score $=($ sample score $/$ best score $) \times 100$ (Seeram et al., 2008). An index value of 100 was assigned for the best score for each test to the best score for each test, and then calculated an index score for all other samples within the test. The average of index scores obtained for all tests for antioxidant capacities was defined as its antioxidant composite index (ACI). All assays were given equal weight, and an overall mean index value was calculated on a normalized basis for each sample.

\section{Statistical analysis}

Data are presented as the mean \pm standard deviation (SD) for triplicate determinations. Differences in the antioxidant activity and total polyphenols, flavonoids and anthocyanins content between cultivars and subsamples were tested by the Tukey's test. Statistical analysis was performed using a statistical package running on a computer (Statistica 8.0, StatSoft, Tulsa, Oklahoma, USA). A probability of $p<0.05$ was considered to be statistically significant (Miller and Miller, 2008).

\section{Results and discussion}

Cyclic voltammograms of analyzed berry fruits were obtained in the potential range $0-800 \mathrm{mV}$ in order to cover all groups of antioxidant compounds and presented in Figure 1. Oxidation potentials of some phenolic compounds are given in Table 1. The first anodic peak appearing between $0.310 \mathrm{~V}$ and $0.350 \mathrm{~V}$ in the cyclic voltammograms of blackberry and raspberry samples could be attributed to the oxidation of flavonols (quercetin and its glucoside) and caffeic acid. As can be seen from the Table 1, cyclic voltammograms of quercetin and quercetin-3-O- $\beta$-glucoside have shown first reversible oxidation peak at Epa $=0.320 \mathrm{~V}$ and Epa $=0.350 \mathrm{~V}$, respectively, which corresponds to the oxidation of the 3'4'-dihydroxy substituent on the B-ring. The second oxidation peak at $0.537 \mathrm{~V}$ of quercetin is probably due to the formation of an intermediate radical produced during the oxidation process. Quercetin and quercetin-3- $O$ - $\beta$-glucoside exhibit almost reversible oxidation steps. The reduction peak of the 3'4'-diquinone formed during quercetin or quercetin-3- $O-\beta$-glucoside oxidation process, appeared at Epc $=0.273 \mathrm{~V}$ and $\mathrm{Epc}=$ $0.318 \mathrm{~V}$, respectively. Caffeic acid also undergoes an irreversible oxidation. The anodic oxidation of caffeic acid show irreversible anodic $($ Epa $=0.344 \mathrm{~V})$ and cathodic $($ Epa $=0.180 \mathrm{~V})$ waves. Several authors have studied the electrochemical oxidation mechanism of caffeic acid (Hotta et al., 2002; Trabelsi et al., 2004). It is generally accepted that oxidation of caffeic acid leads to $o$-quinones via semiquinone forms. Quercetin, quercetin-3- $O$ - $\beta$-glucoside and caffeic acid with two hydroxyl groups at ortho positions with reference to each other showed distinct reduction peaks (Table 1). Thus, these compounds are electrochemically reversible at $\mathrm{pH} 4.5$. Quercetin can donate an electron faster than any other compound tested, because it has the lowest anode peak voltage. 
TABLE 1. Electrochemical data for phenolic compounds.

\begin{tabular}{lcc}
\hline Compound* & $\begin{array}{c}\mathrm{E}_{\mathrm{pa}} \text { vs Ag/AgCl, } \\
(\mathrm{V})^{* *}\end{array}$ & $\begin{array}{c}\mathrm{E}_{\mathrm{ca}} \text { vs Ag/AgCl, } \\
(\mathrm{V})^{* *}\end{array}$ \\
\hline Coumaric acid & 0.759 & - \\
Ferrulic acid & 0.604 & 0.032 \\
Caffeic acid & 0.344 & 0.128 \\
Quercetin & $0.320 ; 0.537$ & 0.273 \\
Rutin & $0.351 ; 0.549$ & - \\
Kaempferol & 0.548 & 0.318 \\
Quercetin-3-O- $\beta$-glucoside & 0.350 & - \\
Malvidin-3-O-glucoside & $0.428 ; 0.543$ & - \\
Cyanidin-3-O-glucoside & $0.529 ; 0.734$ & \\
\hline
\end{tabular}

${ }^{*} \mathrm{C}=1 \mathrm{mmol} \mathrm{L}-1$.

**Sodium acetate-acetic acid buffer $\left(0.1 \mathrm{~mol} \mathrm{~L}^{-1}, \mathrm{pH}=4.5\right)$ in acidified $80 \%$ methanol; scan rate $100 \mathrm{mV} \mathrm{s}^{-1}$.

The second, third and fourth anodic peak detected at potentials between $0.426 \mathrm{~V}$ and $0.444 \mathrm{~V}, 0.524 \mathrm{~V}$ and $0.540 \mathrm{~V}$, and $0.638 \mathrm{~V}$ and $0.756 \mathrm{~V}$, respectively, may be ascribed to anthocyanins and cinnamic acids (ferrulic and coumaric acid). As can be seen from the Table 1, the cyclic voltammogram of malvidin-3-O-glucoside presented two peaks at $0.428 \mathrm{~V}$ and $0.543 \mathrm{~V}$. The first peak is attributed to the oxidation of $-\mathrm{OH}$ group of B-ring, and the second oxidation peak may be due to 5,7-dihydroxyl moiety of A-ring. This is in accordance with literature data for raspberry extracts given by Aguirre et al. (2010). Cyanidin-3-O-glucoside displays two oxidation processes at $\mathrm{E}_{\mathrm{pa}}=0.529 \mathrm{~V}$ and $\mathrm{E}_{\mathrm{pa}}=0.734 \mathrm{~V}$, respectively. These two peaks correspond to 3', ''-OH oxidations in B-ring. Ferrulic and coumaric acids showed two peaks at $0.604 \mathrm{~V}$ and $0.759 \mathrm{~V}$, respectively. The anodic peak appears to correspond to an irreversible process, as no current is observed in the reverse scan. Considering kaempferol, - $\mathrm{OH}$ group presents on the B-ring is responsible for the oxidation peak at $0.548 \mathrm{~V}$. All these results are in accordance with pioneering work that studied the structure-activity relationship of natural antioxidants (Rice-Evans et al., 1996).

The area underneath the anodic peak corresponds to the charge used up in the experiment up to potential of $500 \mathrm{mV}$ $\left(Q_{500}\right)$, and is used as a measure of antioxidants' content pres-

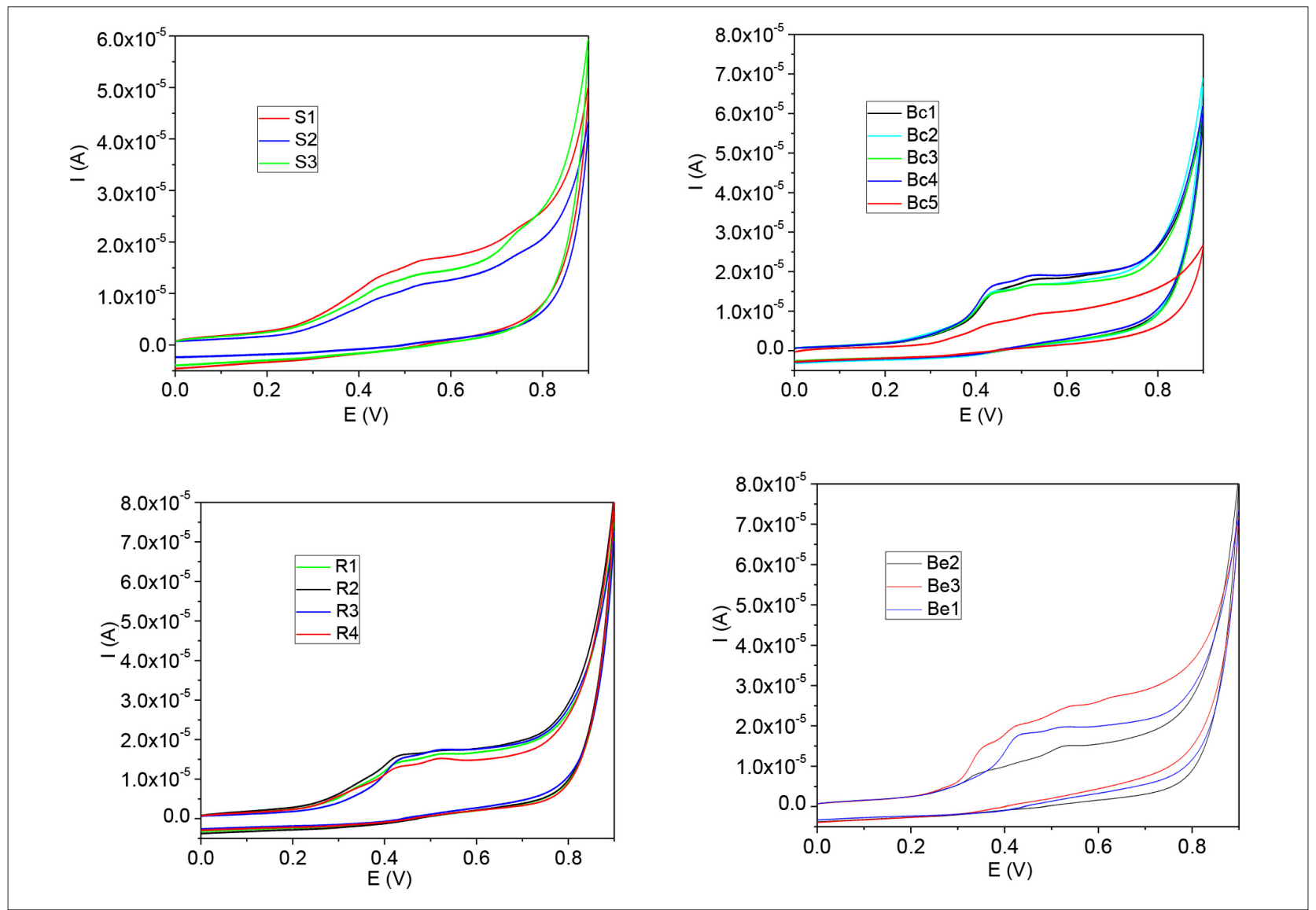

FIGURE 1. Cyclic voltammograms of strawberry (S1-S3), blackberry (Bc1-Bc5), blueberry (Be1-Be3) and raspberry (R1-R4) samples. Operative conditions: sodium acetate-acetic buffer $(\mathrm{pH}=4.5)$ in acidified $80 \%$ methanol; potential up to $800 \mathrm{mV}$; scan rate $100 \mathrm{mV} \mathrm{s}^{-1}$. 
ent in the analyzed sample, i.e., antioxidant capacity. All the peak potentials $\left(E_{p}\right)$ and peak currents $\left(I_{p}\right)$ determined from the cyclic voltammograms as well as $Q_{500}$ and TEAC values of analyzed berry samples are presented in Table 2. From the Table 2 it is evident that the blueberry samples have the highest TEAC, followed by blackberry, raspberry and strawberry samples, which is accordance with its high total anthocyanin and flavonoid contents (Table 3).

As the most natural antioxidants are multifunctional (Manach et al., 2005), the antioxidant capacities of samples cannot be fully described by one single method. In the present study, in addition to electrochemical method (cyclic voltammetry), spectrophotometric techniques such as DPPH radical scavenging activity, 2,2'-azino-bis(3-ethylbenzthiazoline-6-sulphonic acid) radical cation scavenging activity (ABTS), ferric reducing-antioxidant power (FRAP) and re- duction power (RP) were also used to determine antioxidant activity of berry samples. The DPPH, ABTS, FRAP and RP values of berry samples are shown in Table 3. DPPH and ABTS assays are based on the ability of antioxidants to scavenge free radicals, while the FRAP and RP assays are based on the capacity of antioxidants to reduce ferric(III) ions to ferrous(II) ions. DPPH radical scavenging activity and ABTS activity is ranged from $5.05 \mathrm{mmol} \mathrm{TE} \mathrm{g}^{-1}$ to $13.1 \mathrm{mmol} \mathrm{TE} \mathrm{g}^{-1}$ and from $0.2108 \mathrm{mmol} \mathrm{TE} \mathrm{g}^{-1}$ to $0.5462 \mathrm{mmol} \mathrm{TE} \mathrm{g}^{-1}$, respectively. Most of tested berry samples had very close values for ABTS activities. In addition, the values obtained by the DPPH assay were higher than those obtained by the ABTS assay. The antioxidant activity of berry samples measured by the FRAP and RP assays is ranged from $21.2 \mathrm{mmol} \mathrm{FE} \mathrm{g}^{-1}$ to

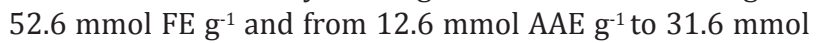
AAE $\mathrm{g}^{-1}$, respectively. Obtained results for FRAP and RP as-

TABLE 2. Peak potential $\left(E_{p}\right)$ and currents $\left(I_{p}\right)$ from cyclic voltammograms of berry fruits.

\begin{tabular}{|c|c|c|c|c|c|c|c|c|c|c|}
\hline \multirow{2}{*}{ Berries } & \multicolumn{4}{|c|}{$\mathrm{E}_{\mathrm{pa}}(\mathrm{V})$} & \multicolumn{4}{|c|}{$\mathrm{I}_{\mathrm{pa}}(\mu \mathrm{A})$} & \multirow{2}{*}{$\mathrm{Q}_{500}(\mu \mathrm{C})$} & \multirow{2}{*}{$\begin{array}{c}\text { TEAC } \\
\left(\mu \mathrm{mol} \text { Trolox } \mathrm{g}^{-1}\right)\end{array}$} \\
\hline & 1 & 2 & 3 & 4 & 1 & 2 & 3 & 4 & & \\
\hline S1 & - & 0.439 & 0.545 & 0.756 & - & 13.0 & 16.6 & 23.0 & 2.70 & 4.596 \\
\hline S2 & - & 0.444 & 0.539 & 0.742 & - & 9.1 & 11.9 & 17.5 & 2.40 & 4.296 \\
\hline S3 & - & 0.442 & 0.540 & 0.750 & - & 11.2 & 13.8 & 22.4 & 2.10 & 4.079 \\
\hline $\mathrm{Bc} 1$ & - & 0.440 & 0.540 & - & - & 15.7 & 18.3 & - & 2.36 & 4.953 \\
\hline $\mathrm{Bc} 2$ & - & 0.437 & 0.539 & 0.650 & - & 15.7 & 16.8 & 17.9 & 2.36 & 4.998 \\
\hline Bc3 & - & 0.435 & 0.534 & - & - & 14.7 & 16.8 & - & 2.20 & 4.579 \\
\hline $\mathrm{Bc} 4$ & - & 0.438 & 0.535 & - & - & 16.3 & 19.1 & - & 3.36 & 5.702 \\
\hline Bc5 & 0.350 & 0.430 & 0.534 & - & 13.1 & 19.5 & 18.2 & - & 5.56 & 10.58 \\
\hline $\mathrm{Be} 1$ & - & 0.433 & 0.528 & - & - & 18.3 & 19.6 & - & 3.45 & 6.041 \\
\hline $\mathrm{Be} 2$ & 0.338 & 0.430 & 0.530 & - & 7.8 & 11.2 & 15.1 & - & 3.83 & 6.590 \\
\hline $\mathrm{Be} 3$ & 0.352 & 0.428 & 0.540 & 0.638 & 14.5 & 20.1 & 2.47 & 27.2 & 5.70 & 9.830 \\
\hline R1 & 0.340 & 0.432 & 0.528 & - & 7.7 & 14.4 & 1.63 & - & 3.60 & 6.116 \\
\hline R2 & 0.337 & 0.434 & 0.540 & - & 8.6 & 16.2 & 1.73 & - & 4.55 & 7.100 \\
\hline R3 & - & 0.432 & 0.526 & - & - & 14.7 & 1.74 & - & 3.05 & 5.043 \\
\hline R4 & 0.310 & 0.426 & 0.524 & - & 6.3 & 12.9 & 1.51 & - & 3.88 & 6.223 \\
\hline
\end{tabular}

TABLE 3. Antioxidant activity, total phenol, flavonoid and anthocyanin contents* in berry fruits.

\begin{tabular}{|c|c|c|c|c|c|c|c|}
\hline Berries & $\begin{array}{c}\text { DPPH } \\
\left(\mathrm{mmol} \mathrm{TE} \mathrm{g}^{-1}\right)\end{array}$ & $\begin{array}{c}\text { ABTS } \\
\left(\mathrm{mmol} \mathrm{TE} \mathrm{g}^{-1}\right)\end{array}$ & $\begin{array}{c}\text { FRAP } \\
\left(\mathrm{mmol} \mathrm{FE} \mathrm{g}^{-1}\right)\end{array}$ & $\begin{array}{c}\text { RP } \\
\left(\mathrm{mmol} \mathrm{AAE} \mathrm{g}^{-1}\right)\end{array}$ & $\begin{array}{l}\text { Total phenols } \\
\left(\mathrm{mg} \mathrm{GAE} \mathrm{g}^{-1}\right)\end{array}$ & $\begin{array}{l}\text { Total flavonoids } \\
\left(\mathrm{mg} \mathrm{CE} \mathrm{g}^{-1}\right)\end{array}$ & $\begin{array}{l}\text { Total anthocyanins } \\
\text { (mg cy-3-glu } 100 \mathrm{~g}^{-1} \text { ) }\end{array}$ \\
\hline S1 & $5.7 \pm 0.0^{\circ}$ & $0.238 \pm 0.001^{p}$ & $24.6 \pm 0.2^{b}$ & $14.7 \pm 0.3^{p}$ & $3.23 \pm 0.03^{s}$ & $0.67 \pm 0.02^{\mathrm{a}}$ & $28.19 \pm 0.03^{c}$ \\
\hline S2 & $5.3 \pm 0.1^{\circ}$ & $0.221 \pm 0.001^{\circ}$ & $23.0 \pm 0.1^{\mathrm{a}}$ & $13.7 \pm 0.0^{\circ}$ & $3.37 \pm 0.09 \mathrm{~s}$ & $0.53 \pm 0.00^{a}$ & $24.34 \pm 0.01^{b}$ \\
\hline S3 & $5.05 \pm 0.05^{a}$ & $0.2108 \pm 0.0006^{a}$ & $21.2 \pm 0.1^{a}$ & $12.6 \pm 0.3^{a}$ & $2.32 \pm 0.08^{a}$ & $0.40 \pm 0.02^{\mathrm{a}}$ & $21.42 \pm 0.01^{a}$ \\
\hline $\mathrm{Bc} 1$ & $7.79 \pm 0.08^{t}$ & $0.2588 \pm 0.0001^{t}$ & $22.6 \pm 0.2^{\mathrm{a}}$ & $19.5 \pm 3^{t}$ & $3.38 \pm 0.00^{u}$ & $0.64 \pm 0.00^{\mathrm{a}}$ & $98.96 \pm 0.01 i$ \\
\hline $\mathrm{Bc} 2$ & $7.6 \pm 0.1^{v}$ & $0.2541 \pm 0.0006^{t}$ & $33.2 \pm 0.2^{z}$ & $19.9 \pm 0.6^{t}$ & $3.6 \pm 0.1^{v}$ & $0.52 \pm 0.00^{\mathrm{a}}$ & $99.19 \pm 0.04$ \\
\hline Bc3 & $7.78 \pm 0.05^{t}$ & $0.2542 \pm 0.0005^{t}$ & $27.9 \pm 0.2^{r}$ & $22.4 \pm 0.1^{\mathrm{e}}$ & $3.5 \pm 0.1^{w}$ & $0.56 \pm 0.02^{\mathrm{a}}$ & $90.49 \pm 0.02^{\mathrm{h}}$ \\
\hline $\mathrm{Bc4}$ & $7.98 \pm 0.05^{t}$ & $0.2544 \pm 0.0006^{t}$ & $39.5 \pm 0.3^{i}$ & $22.9 \pm 0.2^{e}$ & $3.76 \pm 0.02^{v}$ & $0.59 \pm 0.02^{\mathrm{a}}$ & $132.99 \pm 0.01$ \\
\hline Bc5 & $13.1 \pm 0.1^{g}$ & $0.5462 \pm 0.0000^{e}$ & $52.6 \pm 0.3^{h}$ & $31.6 \pm 0.1^{g}$ & $5.96 \pm 0.07^{f}$ & $1.59 \pm 0.03^{c}$ & $365.13 \pm 0.04^{m}$ \\
\hline $\mathrm{Be} 1$ & $7.5 \pm 0.1^{v}$ & $0.3127 \pm 0.0006^{t}$ & $32.0 \pm 0.1^{y}$ & $18.9 \pm 0.1^{d}$ & $3.72 \pm 0.06^{v}$ & $0.63 \pm 0.02^{\mathrm{a}}$ & $242.54 \pm 0.04^{k}$ \\
\hline $\mathrm{Be} 2$ & $8.17 \pm 0.08^{e}$ & $0.3411 \pm 0.0006^{t}$ & $35.3 \pm 0.1^{g}$ & $20.7 \pm 0.2^{\mathrm{e}}$ & $4.37 \pm 0.1^{x}$ & $0.92 \pm 0.05^{\mathrm{a}}$ & $272.5 \pm 0.2^{1}$ \\
\hline Be3 & $12.19 \pm 0.08^{f}$ & $0.5089 \pm 0.0005^{t}$ & $49.0 \pm 0.3^{h}$ & $29.4 \pm 0.2^{f}$ & $5.93 \pm 0.06^{f}$ & $1.57 \pm 0.03^{b}$ & $382.5 \pm 0.1^{n}$ \\
\hline R1 & $7.16 \pm 0.08^{u}$ & $0.253 \pm 0.000^{t}$ & $30.3 \pm 0.1^{t}$ & $17.8 \pm 0.2^{r}$ & $2.82 \pm 0.03^{\circ}$ & $0.52 \pm 0.02^{\mathrm{a}}$ & $58.05 \pm 0.04^{f}$ \\
\hline R2 & $6.1 \pm 0.1^{\circ}$ & $0.2494 \pm 0.0005^{r}$ & $34.5 \pm 0.1^{9}$ & $19.2 \pm 0.2^{d}$ & $4.72 \pm 0.06^{y}$ & $0.64 \pm 0.02^{\mathrm{a}}$ & $70.15 \pm 0.02^{g}$ \\
\hline R3 & $6.25 \pm 0.1^{q}$ & $0.2610 \pm 0.0006^{t}$ & $27.0 \pm 0.2^{p}$ & $16.1 \pm 0.1^{r}$ & $3.0 \pm 0.1^{q}$ & $0.59 \pm 0.00^{\mathrm{a}}$ & $45.88 \pm 0.05^{d}$ \\
\hline R4 & $7.2 \pm 0.1^{u}$ & $0.3220 \pm 0.0006^{t}$ & $31.2 \pm 0.1^{y}$ & $18.4 \pm 0.1^{d}$ & $2.96 \pm 0.08^{\circ}$ & $0.53 \pm 0.02^{\mathrm{a}}$ & $53.53 \pm 0.02^{\mathrm{e}}$ \\
\hline
\end{tabular}

*Values are the mean $\pm \operatorname{SD}(n=3)$. Values with different letters within columns are statistically different at $p<0.05$ using Tukey's test. 


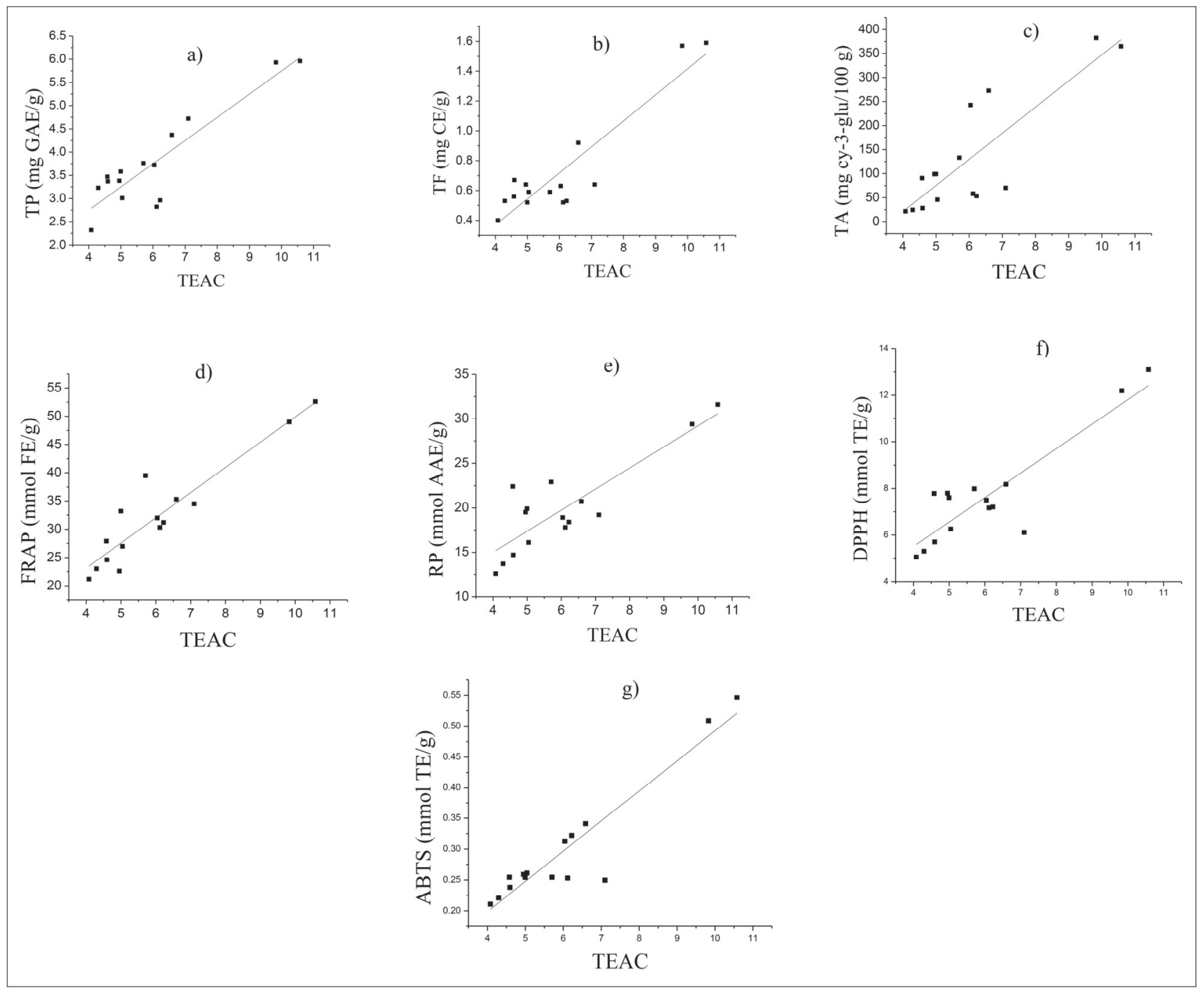

FIGURE 2. Statistical analysis - correlation between the cyclic voltammetry results and different spectrophotometric results: a) total phenols, b) total flavonoids, c) total anthocyanins, d) FRAP, e) RP, f) DPPH, g) ABTS.

TABLE 4. Antioxidant potency composite index of berry samples calculated from five antioxidant capacity measures scaled to relative percentages.

\begin{tabular}{lcccccc}
\hline Berries & DPPH index & ABTS index & FRAP index & RP index & Q $_{500}$ index & ACl \\
\hline S1 & 43.5 & 43.6 & 46.8 & 46.5 & 43.4 & 44.8 \\
S2 & 40.5 & 40.5 & 43.7 & 43.4 & 40.6 & 41.7 \\
S3 & 38.5 & 38.6 & 40.3 & 39.9 & 38.6 & 39.2 \\
Bc1 & 59.5 & 47.4 & 43.0 & 61.7 & 46.8 & 51.7 \\
Bc2 & 58.0 & 46.5 & 63.1 & 63.0 & 47.2 & 55.6 \\
Bc3 & 59.4 & 46.5 & 53.0 & 70.9 & 43.3 & 54.6 \\
Bc4 & 60.9 & 46.6 & 75.1 & 72.5 & 53.9 & 61.8 \\
Bc5 & 100 & 100 & 100 & 100 & 100 & 100 \\
Be1 & 57.3 & 57.3 & 60.8 & 59.8 & 57.1 & 58.5 \\
Be2 & 62.4 & 62.4 & 67.1 & 65.5 & 62.3 & 63.9 \\
Be3 & 93.1 & 93.2 & 93.2 & 93.0 & 92.9 & 93.1 \\
R1 & 54.7 & 46.3 & 57.6 & 56.3 & 57.8 & 54.5 \\
R2 & 46.6 & 45.7 & 65.6 & 60.8 & 67.1 & 57.2 \\
R3 & 47.7 & 47.8 & 51.3 & 50.9 & 47.7 & 49.1 \\
R4 & 55.0 & 59.0 & 59.3 & 58.2 & 58.8 & 58.1 \\
\hline
\end{tabular}


says showed that the antioxidant power of blueberry samples was the highest, followed by the blackberry, raspberry and strawberry samples. This is in accordance with the results of antioxidant obtained from cyclic voltammetry.

Generally, it is known that total polyphenols are highly correlated with antioxidant activity, and the bioavailability of polyphenols has been reported (Manach et al., 2005). The results for total phenolic (TP), total flavonoid (TF) and total anthocyanin (TA) contents in the studied berry samples are presented in Table 3. Total phenolic, flavonoid and anthocyanin contents varied from $2.32 \mathrm{mg} \mathrm{GAE} \mathrm{g}^{-1}$ to $5.96 \mathrm{mg} \mathrm{GAE} \mathrm{g}^{-1}$, from $0.40 \mathrm{mg} \mathrm{CE} \mathrm{g}^{-1}$ to $1.59 \mathrm{mg} \mathrm{CE} \mathrm{g}^{-1}$ and from $21.4 \mathrm{mg}^{\mathrm{cy}}$ 3-glu $100 \mathrm{~g}^{-1}$ to $365 \mathrm{mg}$ cy-3-glu $100 \mathrm{~g}^{-1}$ respectively, among the tested berry samples. Strawberry samples had the lowest content, while blueberry samples had the highest content of total phenols, flavonoids and anthocyanins.

The ACI indices, along with the results from all five antioxidant capacity measures (scaled to relative percentages) are shown in Table 4. The highest ACI have blueberry samples followed by the blackberry, raspberry and strawberry samples which is in accordance with their high total phenols, flavonoids and anthocyanins content and with antioxidant capacity.

Furthermore, strong positive correlations were observed between total phenols, flavonoids, anthocyanins and CV antioxidant capacity $\left(\mathrm{R}^{2}=0.8091, \mathrm{p}=0.0005 ; \mathrm{R}^{2}=0.8341\right.$, $\mathrm{p}=0.0002 ; \mathrm{R}^{2}=0.7163, \mathrm{p}=0.0007$ ), respectively (Figure $2 \mathrm{a}-\mathrm{c})$. In addition, high positive correlations were also found between antioxidant capacities deduced from CVs with those obtained using FRAP $\left(\mathrm{R}^{2}=0.8630, \mathrm{p}=0.0005\right)$, $\mathrm{RP}$ $\left(\mathrm{R}^{2}=0.7426, \mathrm{p}=0.0004\right)$, DPPH $\left(\mathrm{R}^{2}=0.7680, \mathrm{p}=0.0001\right)$ and ABTS $\left(R^{2}=0.8710, p=0.000002\right)$ (Figure $2 d-g$, respectively) indicating that polyphenolic antioxidants with $-\mathrm{OH}$ groups of B-ring are major contributors to the overall antioxidant capacity. This is in accordance with literature data given in review work of Heinonen (2007) that contribution of anthocyanins to the antioxidant effect of berries is significant. The highest degree of positive correlation was observed between total phenols and FRAP, which may be attributed to an electron transfer based mechanism governing these two assays. Also, Firuzi et al. (2005) found that the $o$-dihydroxy structure in the B-ring and the 3-hydroxy group and 2,3-double bond in the $\mathrm{C}$-ring give the highest contribution to the FRAP antioxidant activity.

Differences in the TP, TF and TA as well as antioxidant activity observed among cultivars and subsamples were tested by the Tukey's test, respectively. Similarly to the polyphenols, flavonoids and anthocyanins content, the antioxidant activity of berry samples showed significant differences depending on cultivars. According to the literature data (Connor et al., 2002; Anttonen and Karjalainen, 2005; Anttonen et al., 2006; Milošević et al., 2012), cultivar and different growing environments as well as agricultural and climatic factors contribute to the phenolic status in plants.

\section{Conclusion}

The results obtained in this work by electrochemical method indicate that cyclic voltammetry is a good technique for the characterization of the antioxidant properties of berry samples. Furthermore, CV is based only on the chemical/ physical properties of the molecules and does not require the use of reactive species. The capability of the method to rapidly evaluate the antioxidant activity of berries could be useful for food industry. The high degree of positive correlation with the spectrophotometry antioxidant capacity measures indicates that the results derived from $\mathrm{CV}$ are reliable and comparable to the results of other spectrophotometric methods (FRAP, RP, DPPH and ABTS). This finding clearly indicates that the CV method as a suitable method for the determination of the reducing capacity based on the electrochemical properties of compounds under the test. A pronounced anodic current peak observed between $0.524 \mathrm{~V}$ and $0.540 \mathrm{~V}$ in all analyzed berry samples can be ascribed to anthocyanins, which are the major contributors to the antioxidant capacity of investigated berries. Obtained values for ACI parameter provides easy comparison of antioxidant capacity among tested berries. The highest ACI had blueberry samples, followed by blackberry, raspberry and strawberry samples.

\section{Acknowledgments}

This research was supported by grant numbers 172047 and 41018 from the Serbian Ministry of Education, Science and Technological Development. The authors are grateful for the financial support provided by this Ministry.

\section{References}

Aguirre, M.J., Chen, Y.Y., Isaacs, M., Matsuhiro, B., Mendoza, L., and Torres, S. (2010). Electrochemical behavior and antioxidant capacity of anthocyanins from Chilean red wine, grape and raspberry. Food Chem. 121, 44-48. https://doi.org/10.1016/j. foodchem.2009.11.088.

Anttonen, M.J., and Karjalainen, R.O. (2005). Environmental and genetic variation of phenolic compounds in red raspberry. J. Food Comp. Anal. 18, 759-769. https://doi.org/10.1016/j. jfca.2004.11.003.

Anttonen, M.J., Hoppula, K.I., Nestby, R., Verheul, M.J., and Karjalainen, R.O. (2006). Influence of fertilization, mulch color, early forcing, fruit order, planting date, shading, growing environment, and genotype on the contents of selected phenolics in strawberry (Fragaria $\times$ ananassa Duch.) fruits. J. Agric. Food Chem. 54, 2614-2620. https:// doi.org/10.1021/jf052947w.

Arts, M.J.T.J., Haenen, G.R.M.M., Voss, H.P., and Bast, A. (2004). Antioxidant capacity of reaction products limits the applicability of the trolox equivalent antioxidant capacity (TEAC) assay. Food Chem. Toxicol. 42, 45-49. https://doi.org/10.1016/j.fct.2003.08.004.

Benzie, I.F.F., and Strain,J.J. (1999). Ferric reducing/antioxidant power assay: Direct measure of total antioxidant activity of biological and modified version for simultaneous measurement of total antioxidant power and ascorbic acid concentration. Methods Enzymol. 299, 1527. https://doi.org/10.1016/S0076-6879(99)99005-5.

Brand-Williams, W., Cuvelier, M.E., and Berset, C. (1995). Use of a free radical method to evaluate antioxidant activity. Lebensm. Wiss. Technol. 28, 25-30. https://doi.org/10.1016/S00236438(95)80008-5.

Chen, F., Sun, Y., Zhao, G., Liao, X., Hu, X., Wu, J., and Wang, Z. (2007). Optimization of ultrasound-assisted extraction of anthocyanins in red raspberries and identification of anthocyanins in extract using high-performance liquid chromatography-mass spectrometry. Ultrason. Sonochem. 14, 767-778. https://doi.org/10.1016/j. ultsonch.2006.12.011.

Connor, A.M., Luby, J.J., and Tong, C.B.S. (2002). Genotypic and environmental variation in antioxidant activity, total phenolic content, and anthocyanin content among blueberry cultivars. J. Am. Soc. Hortic. Sci. 127, 89-97. https://doi.org/10.21273/JASHS.127.1.89.

Firuzi, O., Lacanna, A., Petrucci, R., Marrosu, G., and Saso, L. (2005). Evaluation of the antioxidant activity of flavonoids by "ferric reducing antioxidant power" assay and cyclic voltammetry. Biochim. Biophys. Acta 1721, 174-184. https://doi.org/10.1016/j. bbagen.2004.11.001. 
Giampieri, F., Tulipani, S., Alvarez-Suarez, J.M., Quiles, J.L., Mezzetti, B., and Battino, M. (2012). The strawberry: Composition, nutritional quality, and impact on human health. Nutrition 28,9-19. https://doi. org/10.1016/j.nut.2011.08.009.

Guisti, M.M., and Wrolstad, R.E. (2001). Characterization and measurement of anthocyanins by UV-visible spectroscopy. Curr. Prot. Food Anal. Chem. F1.2.1-F1.2.13. https://doi.org/10.1002/ 0471142913.faf0102s00.

Halvorsen, B.L., Holte, K., Myhrstad, M.C.W., Barikmo, I., Hvattum, E. Remberg, S.F., Wold, A.B., Haffner, K., Baugerod, H., Andersen, L.F., Moskaug, O., Jacobs Jr., D.R., and Blomhoff, R. (2002). A systematic screening of total antioxidants in dietary plants. J. Nutr. 132, 461471. https://doi.org/10.1093/jn/132.3.461.

Heinonen, M. (2007). Antioxidant activity and antimicrobial effect of berry phenolics - A Finnish perspective. Mol. Nutr. Food Res. 51, 684-691. https://doi.org/10.1002/mnfr.200700006.

Hotta, H., Ueda, M., Nagano, S., Tsvjino, Y., and Koyama, J. (2002) Mechanistic study of the oxidation of caffeic acids by digital simulation of cyclic voltammograms. Anal. Biochem. 303, 66-72. https://doi.org/10.1006/abio.2002.5577.

Ivanovic, J., Tadic, V., Dimitrijevic, S., Stamenic, M., Petrovic, S., and Zizovic, I. (2014). Antioxidant properties of the anthocyanincontaining ultrasonic extracts from blackberry cultivar 'Čačanska Bestrna'. Ind. Crop Prod. 53, 274-281. https://doi.org/10.1016/j. indcrop.2013.12.048.

Lee, J., Dossett, M., and Finn, C.E. (2012). Rubus fruit phenolic research: The good, the bad, and the confusing. Food Chem. 130, 785-796. https://doi.org/10.1016/j.foodchem.2011.08.022.

Manach, C., Williamson, G., Morand, C., Scalbert, A., and Remesy, C. (2005). Bioavailability and bioefficacy of polyphenols in humans. I. Review of 97 bioavailability studies. Am. J. Clin. Nutr. 81, 230S-242S. https://doi.org/10.1093/ajcn/81.1.230S.

Miller, J.N., and Miller, J.C. (2005). Statistics and Chemometrics for Analytical Chemistry (London, England: Pearson Education).

Milošević, T., Milošević, N., Glišić, I., and Mladenović, J. (2012). Fruit quality attributes of blackberry grown under limited environmental conditions. Plant Soil Environ. 58, 322-327. https:// doi.org/10.17221/33/2012-PSE.

Nile, S.H., and Park, S.W. (2014). Edible berries: Bioactive components and their effect on human health. Nutrition 30,134-144. https://doi. org/10.1016/j.nut.2013.04.007.

Oancea, S., Grosu, C., Ketney, O., and Stoia, M. (2013). Conventional and ultrasound assisted extraction of anthocyanins from blackberry and sweet cherry cultivars. Acta Chim. Slov. 60, 383-389.

Oyaizu, M. (1986). Studies on products of browning reaction: antioxidative activity of products of browning reaction prepared from glucosamine. Jpn. J. Nutr. 44, 307-315. https://doi.org/10.5264/ eiyogakuzashi.44.307.

Paredes-López, O., Cervantes-Ceja, M.L., Vigna-Pérez, M., and Hernández-Pérez, T. (2010). Berries: Improving human health and healthy aging, and promoting quality life - A review. Plant Food Hum. Nutr. 65, 299-308. https://doi.org/10.1007/s11130-010-0177-1.

Piljac-Zegarac, J., Valek, L., Stipcevic, T., and Martinez, S. (2010). Electrochemical determination of antioxidant capacity of fruit tea infusions. Food Chem. 121, 820-825. https://doi.org/10.1016/j. foodchem.2009.12.090

Rao, A.V., and Snyder, D.M. (2010). Raspberries in human health: A review. J. Agric. Food Chem. 58, 3871-3883. https://doi. org/10.1021/jf903484g.

Re, R., Pellegrini, N., Proteggente, A., Pannala, A., Yang, M., and RiceEvans, C. (1999). Antioxidant activity applying an improved ABTS radical cation decolonization assay. Free Radic. Biol. Med. 26, 12311237. https://doi.org/10.1016/S0891-5849(98)00315-3.

Rice-Evans, C.A., Miller, N.J., and Paganga, G. (1996). Structure antioxidant activity relationship of flavonoids and phenolic acids. Free Rad. Bio. Med. 20, 933-956. https://doi.org/10.1016/08915849(95)02227-9.

Seeram, N.P. (2008a). Berry Fruits: Compositional elements, biochemical activities, and the impact of their intake on human health, performance, and disease. J. Agric. Food Chem. 56, 627-629. https://doi.org/10.1021/jf071988k.

Seeram, N.P. (2008b). Berry fruits for cancer prevention: Current status and future prospects. J. Agric. Food Chem. 56, 630-635. https://doi.org/10.1021/jf072504n.

Seeram, N.P., Aviram, M., Zhang, Y., Henning, S.M., Feng, L., Dreher, M., and Heber, D. (2008). Comparison of antioxidant potency of commonly consumed polyphenol-rich beverages in the United States. J. Agric. Food Chem. 56, 1415-1422. https://doi.org/10.1021/ jf073035s.

Singleton, V.L., Orthofer, R., and Lamuela-Raventos, R.M. (1999). Analysis of total phenols and other oxidation substrates and antioxidants by means of Folin-Ciocalteu reagent. Meth. Enzymol. 299, 152-178. https://doi.org/10.1016/S0076-6879(99)99017-1.

Slinkard, K., and Singleton, V.L. (1977). Total phenol analysis: automation and comparison with manual methods. Am. J. Encl. Vitic. $28,49-55$.

Stratil, P., Klejdus, B., and Kuban, V. (2006). Determination of total content of phenolic compounds and their antioxidant activity in vegetables-evaluation of spectrophotometric methods. J. Agric. Food Chem. 54, 607-616. https://doi.org/10.1021/jf052334j.

Szajdek, A., and Borowska, E.J. (2008). Bioactive compounds and health-promoting properties of berry fruits: A review. Plant Food Hum. Nutr. 63, 147-156 https://doi.org/10.1007/s11130-008-0097-5.

World Health Organization (2002). The World Health Report Reducing Risk and Promoting Healthy Life (Geneva: World Health Organization).

Trabelsi, S.K., Tahar, N.B., and Abdelhedi, R. (2004). Electrochemical behavior of caffeic acid. Electrochim. Acta 49, 1647-1654. https:// doi.org/10.1016/S0013-4686(03)00995-2.

Tulipani, S., Mezzetti, B., Capocasa, F., Bompadre, S., Beekwilder, J., Ric de Vos, C.H., Capanoglu, E., Bovy, A., and Battino, M. (2008). Antioxidants, phenolic compounds, and nutritional quality of different strawberry genotypes. J. Agric. Food Chem. 56, 696-704. https://doi.org/10.1021/jf0719959.

Veljković, J., Pavlović, A., Mitić, S., Tošić, S., Stojanović, G., Kaličanin, B., Stanković, D., Stojković, M., Mitić, M., and Brcanović, J. (2013). Evaluation of individual phenolic compounds and antioxidant properties of black, green, herbal and fruit tea infusions consumed in Serbia: spectrophotometrical and electrochemical approaches. J. Food Nutr. Res. 52, 12-24.

Wang, S.Y., and Millner, P. (2009). Effect of different cultural system on antioxidant capacity, phenolic content, and fruit quality of strawberries (Fragaria $\times$ ananassa Duch.). J. Agric. Food Chem. 57, 9651-9657. https://doi.org/10.1021/jf9020575.

Yang, B., Kotani, A., Rarai, K., and Kusu, F. (2001). Estimation of the antioxidant activities of flavonoids from their oxidation potentials. Anal. Sci. 17, 599-604. https://doi.org/10.2116/analsci.17.599.

Zhishen, J., Mengcheng, T., and Wu Jianming, W. (1999). The determination of flavonoids content in mulberry and scavenging effect on superoxide radicals. Food Chem. 64, 555-559. https://doi. org/10.1016/S0308-8146(98)00102-2. 
Received: Sep. 17, 2017

Accepted: Apr. 18, 2018

Addresses of authors:

Milena D. Nikolić ${ }^{1}$, Aleksandra N. Pavlovićc1,*,

Snežana S. Mitić ${ }^{1}$, Snežana B. Tošić ${ }^{1}$, Milan N. Mitić ${ }^{1}$

Biljana M. Kaličanin², Dragan D. Manojlovićs

and Dalibor M. Stanković ${ }^{4,5}$

${ }^{1}$ University of Niš, Faculty of Sciences and Mathematics,

Department of Chemistry, Višegradska 33, P.O. Box 224, 18000 Niš, Serbia

${ }^{2}$ University of Niš, Faculty of Medicine, Department of

Pharmacy, Blvd. Dr Zorana Đinđića 81, 18000 Niš, Serbia

${ }^{3}$ University of Belgrade, Faculty of Chemistry, Department of Analytical Chemistry, Studentski trg 12-16,

11000 Belgrade, Serbia

${ }^{4}$ University of Belgrade, The "Vinča" Institute of Nuclear

Sciences, P.O. Box 522, 11001 Belgrade, Serbia

${ }^{5}$ University of Belgrade, Innovation center of the Faculty of Chemistry, P.O. Box 522, 11001 Belgrade, Serbia

* Corresponding author;

E-mail: aleksandra.pavlovic@pmf.edu.rs

Tel.: +381 18 533-015; fax: +381 18 533-014 